\title{
Formas tratamentais em cartas escritas em Pernambuco (1869-1969): tradição discursiva e sociopragmática ${ }^{1}$
}

\section{Forms of address in letters written in pernambuco (1869-1969): discursive tradition and sociopragmatic}

\author{
Valéria Severina Gomes ${ }^{2}$ \\ Universidade Federal Rural de Pernambuco (UFRPE), Recife, Pernambuco, Brasil. \\ lelavsg@gmail.com
}

Célia Regina dos Santos Lopes ${ }^{3}$

Universidade Federal do Rio de Janeiro (UFRJ), Rio de Janeiro, Rio de Janeiro, Brasil. celiar.s.lopes@gmail.com

Resumo: Este estudo objetiva analisar as formas de tratamento de base nominal e pronominal localizadas em cartas escritas em Pernambuco, entre o século $19 \mathrm{e}$ o século 20 (1869-1969). O intuito é observar a distribuição dessas formas, com base na teoria do Poder e da Solidariedade (BROWN; GILMAN, 1960), a Teoria da Polidez (BROWN; LEVINSON, 1987), a Tradição Discursiva (KABATEK, 2006) e a Sociolinguística Histórica (CONDE-SILVESTRE, 2007). Os resultados mostraram que as formas de tratamento nominal (Vossa Mercê e $O$ Senhor) ainda eram usadas por motivações pragmáticas e pela natureza do texto no século 19 e que houve um aumento progressivo de uso da nova forma (você) em quase todos os tipos de relações sociais ao longo do tempo.

Palavras-chave: cartas pernambucanas, formas de tratamento nominal e pronominal, segunda pessoa.

${ }^{1}$ Este estudo foi desenvolvido durante o estágio de pós-doutoramento da primeira autora, realizado no período de nov. / 2013 a out. / 2014. O estágio foi supervisionado pela segunda autora (II/Pq $2 \mathrm{CNPq}$ ) e foi financiado pelo CNPq, Pós-doutorado Júnior - PDJ.

${ }^{2}$ Bolsista de Pós-Doutorado Júnior do CNPq.

${ }^{3}$ Bolsista de Produtividade do CNPq. 
Abstract: This paper aims to analyze the nominal and pronominal forms of address found in letters written in state of Pernambuco (Brazil) in the $19^{\text {th }}$ century and the $20^{\text {th }}$ century (from 1869 to 1969). We intend to observe the distribution of forms of address, according to the theory of Power and Solidarity (BROWN; GILMAN, 1960), Politeness Theory (BROWN; LEVINSON, 1987), Discursive Tradition (KABATEK, 2006), the Historical Sociolinguistics (CONDE-SILVESTRE, 2007. The results showed that the nominal address forms (Vossa Mercê e $O$ Senhor) were still used by pragmatic motivations and by the nature of the text in the $19^{\text {th }}$ century and a progressive increase in the use of the form voce in almost all types of social relations over time.

Keywords: letters from Pernambuco (Brazil), nominal and pronominal forms of address, second person.

Recebido em: 11 de outubro de 2014. Aprovado em: 23 de fevereiro de 2015.

\section{Introdução}

A forma você, advinda do processo de gramaticalização de Vossa Mercê, século 15 (RUMEU, 2004), assumiu, na passagem do século 19 ao 20, um comportamento híbrido, ora guardando o caráter cerimonioso da forma originária, ora assumindo um caráter mais informal em variação com o tu-íntimo. A passagem do você de forma tratamental de base nominal para forma tratamental pronominal promoveu a existência simultânea de diferentes subsistemas de representação de segunda pessoa do singular no Português Brasileiro (PB) (LOPES; CAVALCANTE, 2011).

O presente estudo investiga, adotando a perspectiva de Lopes (2011, 2013), o comportamento variável das formas de $2^{\mathrm{a}}$ pessoa de base nominal e pronominal em documentação relativa a Pernambuco. Discutimos os resultados obtidos com base em cartas pessoais de autores pernambucanos dos séculos 19 e 20, com o intuito de adicioná-los aos estudos anteriores sobre as formas tratamentais do português brasileiro (PB) (LOPES; DUARTE, 2003; RUMEU, 2008, 2013; BARCIA, 2006; 
LOPES, RUMEU, CARNEIRO, 2013; entre outros). Na análise, serão levados em consideração:

a) a relevância do conceito das Tradições Discursivas na explicação das mudanças ocorridas no sistema de tratamento pronominal do português brasileiro;

b) os contextos sociopragmáticos que favoreciam o emprego das formas você e tu como sujeito em 100 anos de produção escrita pernambucana (1869-1969); e

c) a variação entre tu e você na posição de sujeito em cartas dos âmbitos familiar, pessoal e amorosa dessa localidade ainda não contemplada pelos trabalhos sobre a sociolinguística histórica do quadro pronominal do português brasileiro.

Optamos, para este artigo, por uma discussão em quatro seções. Na primeira, apresentamos a base teórico-metodológica adotada para, na sequência, descrever o corpus, a constituição das cartas pessoais e o perfil dos escreventes. Na terceira seção, discutimos brevemente as motivações de uso das raras formas nominais de tratamento encontradas nas cartas mais remotas da amostra. Na quarta, analisamos os dados de $t u$ e você na posição de sujeito nos eixos cronológico e social. Por fim, tecemos algumas considerações sobre os resultados obtidos e as referências utilizadas.

\section{Breve enquadramento teórico-metodológico e hipótese norteadora}

Para atingir os propósitos mencionados anteriormente, adotamos uma abordagem que envolve a interface entre os pressupostos da pragmática sociocultural e histórica (Teoria da Polidez e Sociolinguística Histórica), associadas ao conceito de Tradição Discursiva (BROWN; LEVINSON, 1987; CONDE-SILVESTRE， 2007; KOCH， 2008; KABATEK, 2006).

À luz da Teoria da Polidez, idealizada por Brown e Levinson (1987), estamos levando em conta que, durante uma interação, os 
interlocutores fazem uso de estratégias de polidez, por exemplo, as formas tratamentais, para manter preservada a própria face e a do outro. Tais recursos funcionam como formas mitigadoras dos atos de fala que por si só são considerados ameaçadores à face do interlocutor. Os autores fazem uma distinção entre face positiva (face) e face negativa (território). ${ }^{4}$ A ideia elementar é a de que a interação é o lugar do conflito e as estratégias de polidez são recursos para evitá-lo. Assim é preciso lidar com a preservação pessoal e o modo como se é visto socialmente.

Do ponto de vista da Sociolinguística Histórica, a discussão dos dados transita da análise quantitativa à análise qualitativa com base nos fatores pragmáticos e nos papéis sociais dos interlocutores (CONDESILVESTRE, 2007) que condicionam a opção por certas formas tratamentais e variantes. No âmbito da Sociolinguística Histórica ( $O p$. cit.), são aplicados alguns princípios da sociolinguística sincrônica para o estudo e interpretação dos dados do passado. É preciso considerar, entretanto, as especificidades e as dificuldades enfrentadas nos trabalhos com fontes históricas. Não basta, para as análises da sociolinguística histórica, a simples transposição da metodologia de base laboviana. Os estudos de sociolinguística histórica enfrentam diversos problemas para a análise de textos de sincronias passadas, uma vez que a informação sobre as fontes que nos chegam às mãos é "fragmentária, escassa e dificilmente vinculável com a produção real de seus falantes" (CONDE-SILVESTRE, 2007, p. 35). Um dos problemas centrais está relacionado à constituição da amostra. Os dados são procedentes de textos escritos que sobreviveram na atualidade 'por sorte'. Isso significa, por exemplo, que o controle de fatores externos, como faixa etária, escolaridade, gênero, categoria social, pode ser lacunar, pois os informantes não estão mais à disposição do investigador como ocorre nos estudos sincrônicos. Os dados costumam se restringir aos grupos alfabetizados da comunidade, em geral, constituídos por homens com status médio a alto. Além disso, só determinados estilos e registros são recuperáveis nos acervos; nem sempre a amostra para análise é homogênea. Em diversos estudos de sociolinguística histórica, como o que propomos aqui, a análise é feita

\footnotetext{
${ }^{4}$ Para o conceito de faces, ver Goffman (1980) e Brown e Levinson (1987).
} 
com base nas frequências brutas dos fatores linguísticos e sociais controlados, porque nem todas as "células" puderam ser preenchidas. 5 Outra diferença básica é que o "resultado" da mudança linguística, diferentemente do que ocorre na análise da sociolinguística sincrônica, já é conhecido pelo analista histórico. O propósito, assim, é distinto, porque o objetivo é tentar acompanhar o processo de mudança em suas diversas etapas, observando as tendências do comportamento linguístico com base na amostra escrita constituída. A descoberta de novos materiais sempre poderá elucidar as lacunas observadas nos estudos parciais feitos com os dados disponíveis.

No viés sociopragmático, procuraremos identificar a motivação e a intencionalidade comunicativa embutida na forma de tratamento escolhida pelos missivistas da amostra, baseado no controle do tipo de relação social existente entre remetente e destinatário. Para tanto, será revisitada a clássica dicotomia "poder e solidariedade" proposta inicialmente por Brown e Gilman (1960) e seguidores. Em termos amplos, o parâmetro do poder refere-se ao controle que umas pessoas exercem sobre outras em uma determinada situação interativa, o que pode desembocar em uma assimetria tratamental. Como a relação de poder entre duas pessoas não é recíproca, elegem-se certas formas de tratamento diferentes em função da hierarquia que se estabelece entre os interlocutores. O parâmetro da Solidariedade estabelece o mesmo nível na hierarquia social: a igualdade entre as pessoas. Nesse tipo de relação, em geral, se outorga o uso mútuo do $T U^{6}$ (recíproco ou igualitário), logo o uso simétrico de $T U$ configuraria intimidade (sentimento de solidariedade entre os participantes da situação comunicativa). Estabeleceram-se, para este estudo, os tipos básicos de relação com ênfase nas relações de parentesco e entre amigos:

a) Relações assimétricas descendentes (de superior para inferior): pai-filho, mãe-filho.

\footnotetext{
${ }^{5}$ Para detalhes sobre os limites e problemas enfrentados pela Sociolinguística Histórica, veja Conde-Silvestre (2007), Hernández-Campoy e Conde-Silvestre (2012).

${ }^{6}$ A oposição é estabelecida entre o $t u$ [+ familiar] e vous [+ polido] ou $T / V$, utilizando o francês como padrão, embora em cada língua exista o mesmo tipo de tratamento com formas variantes e diversificadas.
} 
b) Relações assimétricas ascendentes (de inferior para superior): filho-pai, filho-mãe.

c) Relações simétricas (solidárias): entre amigos, entre namorados, cônjuges.

Com a perspectiva das Tradições Discursivas verificamos que as escolhas do sistema tratamental, na virada do século 19 ao 20, são motivadas também pela natureza e pela historicidade do texto, neste caso pela natureza das cartas pessoais. Partimos, então, do entendimento de que Tradição Discursiva (TD)

é a repetição de um texto ou de uma forma textual ou de uma maneira particular de escrever ou falar que adquire valor de signo próprio (portanto é significável). Pode-se formar em relação a qualquer finalidade de expressão ou qualquer elemento de conteúdo, cuja repetição estabelece uma relação de união entre atualização e tradição; qualquer relação que se pode estabelecer semioticamente entre dois elementos de tradição (atos de enunciação ou elementos referenciais) que evocam uma determinada forma textual ou determinados elementos lingüísticos empregados. (KABATEK, 2006, p. 157).

A relevância da incorporação do modelo de Tradição Discursiva ao tripé de sustentação teórica desta pesquisa advém do fato de tal perspectiva, no processo analítico sócio-histórico dos usos linguísticos, contribuir com a distinção entre as ocorrências que retratam a norma vigente no período estudado e as fórmulas fixas, convencionalizadas em determinado gênero particular. ${ }^{7}$

\footnotetext{
${ }^{7}$ Um bom exemplo de uso linguístico convencionalizado em um determinado gênero particular é o caso do emprego predominante da forma tratamental vós nos benditos do município de Lajes/RN, estudados pelo Professor Lucrécio Araújo de Sá Júnior. A segunda pessoa do plural mantém-se conservada nesses cânticos religiosos da tradição cultural popular como uma forma tradicional de tratamento cerimonioso e assimétrico entre os fiéis e a Divindade evocada.
} 
Para a proposta de análise adotada neste artigo, defendemos, com Koch (2008), que certos atos linguísticos diretivos, como um pedido, uma ordem, uma recomendação, seriam atos ameaçadores, já que pressupõem uma ação futura do ouvinte / destinatário. Por essa razão, constituem uma intromissão no "território" do outro (GOFFMAN, 1967, apud KOCH, 2008). O "tratamento nominal abstrato" (Vossa Mercê) teria herdado o caráter indireto e atenuante da estratégia nominal de tratamento, por isso seria menos invasivo, menos "ameaçante ao interlocutor", ao passo que um pronome de segunda do singular $(t u)$ pode ser um ato de ameaça à face negativa do interlocutor (BROWN E LEVINSON, 1987) quando a forma pronominal não funciona como uma estratégia mitigadora à imposição do ato $(\mathrm{KOCH}, 2008$, p. 59). As línguas, no geral, apresentam procedimentos distintos de cortesia para evitar ou atenuar essas ameaças pragmáticas, como ocorre com os tratamentos abstratos de base nominal (Vossa Mercê, Vossa Majestade, $O$ Senhor, etc) ou mesmo com a pluralização do pronome (o emprego de vós no lugar de $t u$ ). Nos dois casos a referência se dá a um grupo mais amplo, a uma entidade abstrata ou a uma qualidade do interlocutor. Adotando tal perspectiva, defendemos que a forma pronominal você pode ter mantido algum valor de cortesia, formalidade, distanciamento ou indiretividade advinda de Vossa Mercê. Nesse sentido, o seu emprego no lugar do tratamento direto $t u$ poderia ser uma estratégia de polidez/cortesia, em fins do século XIX, que foi se espraiando com maior ou menor velocidade pelo PB ao assumir os contextos antes destinados ao íntimo e solidário $t u$. Pela preservação de alguns traços originais, você tornou-se uma estratégia de referência neutra, ou seja, uma estratégia "coringa" para os novos papéis sociais das sociedades contemporâneas.

\section{Constituição das cartas e o perfil dos escreventes}

Para explicar processos históricos de mudança é preciso o registro nos textos escritos. Como explica Maia (2012, p. 537):

Uma vez que consideramos que a história da língua deve depreender-se dos textos que nela se escreveram e do conhecimento da história dos mesmos [sic.] e, 
portanto, que a sua construção deve ter o imprescindível apoio das fontes textuais, a constituição de corpora é uma exigência da pesquisa diacrónica.

Com o propósito de relacionar a historicidade da língua e do texto com base no conceito de Tradição Discursiva, a carta pessoal tem servido de base a inúmeras pesquisas diacrônicas em virtude da característica que tende à informalidade, pela diversidade temática, pela recorrência dos seus elementos constitutivos, pelo caráter diverso dos interlocutores, pela variedade dos propósitos comunicativos, etc., ocupando, de acordo com essas características e com outras, diferentes espaços no contínuo da proximidade à distância comunicativa.

Para traçar esse contínuo entre a imediatez e a distância comunicativas Koch e Osterreicher (2007) estabeleceram os parâmetros que determinam um grande número de formas comunicativas e que definem diferentes combinações das condições comunicativas que estabelecem os dois polos. Os autores postulam que as formas comunicativas passam por dois meios dicotômicos de realização, o fônico e o gráfico, e a concepção dessas formas comunicativas ocorre no contínuo das extremidades falada (proximidade comunicativa) e escrita (distância comunicativa). A carta de caráter mais pessoal prototípica, por exemplo, tem concepção falada e meio de realização gráfico e apresenta uma combinação paramétrica que favorece a proximidade comunicativa no que diz respeito à privacidade, à familiaridade entre os interlocutores, à emocionalidade, à espontaneidade relativa e ao desenvolvimento temático livre. Daí a carta pessoal ter um caráter de "conversação escrita".

Pesquisas anteriores têm demonstrado que o gênero textual tem influência no emprego da forma tratamental (RUMEU, 2008; LOPES, 2011). Nesse sentido, concordamos com Souza (2012), ao considerar o gênero carta pessoal um hiperônimo que abrange os subgêneros: carta amorosa, familiar e pessoal (esta última mantém o rótulo por falta de um nome mais preciso e inclui apenas as cartas não-familiares trocadas, geralmente, entre amigos). Em cada subgênero desses, há níveis diferentes de intimidade entre remetente e destinatário, o que acarreta no 
maior ou menor grau de cumplicidade, de afetividade, de expressividade, com implicação direta na escolha do tratamento a ser empregado.

As cartas pessoais pernambucanas que compõem o corpus desta pesquisa, coletadas na Fundação Joaquim Nabuco, em Recife, seguem, como os demais textos dessa tradição discursiva, um padrão composicional reconhecido que ancora o texto: o local, a data, o vocativo, a captação de benevolência, o corpo do texto, a despedida e a assinatura. Por meio dessas cartas, passamos a conhecer o entorno de quem as escreveu, sobre o local onde vivia, quando escreveu, além obviamente de podermos identificar as estratégias linguísticas utilizadas. Essas estratégias expressam as variantes linguísticas de acordo com o tempo histórico, o local, o perfil social dos envolvidos, por vezes escasso, e da natureza tradicional do texto. Outro traço significativo na constituição das cartas é o conhecimento partilhado entre remetente e destinatário acerca de saberes variados e sobre temáticas diversas. Esses e outros traços fazem parte do acervo das correspondências ativas e passivas de Pernambuco entre os séculos 19 e 20.

Para esta pesquisa, coletamos 123 cartas, compreendidas no período de 1869 a 1969 (séculos 19 e 20), divididas nos seguintes subgêneros: 83 cartas familiares, 32 cartas pessoais (entre amigos) e 8 cartas amorosas. Essa amostra totalizou 47.500 palavras. Foram levantados acervos de 11 famílias: Arthur Orlando - político e jornalista (22 cartas no período de 1894 a 1929)-, José Mariano - líder abolicionista, político e jornalista (5 cartas no período de 1869 a 1900)-, Joaquim Nabuco - político, diplomata, jornalista e jurista (17 cartas no período de 1872 a 1909)-, Arnaldo Guedes - não identificado (2 cartas no período de 1922 a 1930), Ascenso Ferreira - poeta (1 carta de 1962), Gilberto Freyre - sociólogo e escritor (10 cartas no período de 1939 a 1969), Manoel Borba - promotor, político e industrial (16 cartas no período de 1923 a 1924), Mário Sette - escritor e professor de Filosofia (13 cartas no período de 1905 a 1937), Nelson Ferreira - compositor e maestro (1 carta de 1925), Waldemar de Oliveira - médico, escritor, teatrólogo e compositor (28 cartas no período de 1907 a 1917) e Breno Braga - major do Exército brasileiro (8 cartas no período de 1941 a 1948). 
As cartas coletadas constituem a produção escrita de pessoas ilustres com um alto grau de escolaridade e letramento. Essa informação é bastante significativa para justificar o padrão predominantemente regular dos usos linguísticos identificados com relação às formas tratamentais. No entanto, nesse conjunto de cartas de escreventes ilustres, também são encontradas correspondências de outros familiares e amigos que ampliam a margem de verificação de contextos de variação das formas tratamentais $t u$ e você. Nas próximas seções, daremos o resultado geral das formas na posição de sujeito e discutiremos qualitativamente os poucos dados referentes às formas oriundas de sintagmas nominais, as denominadas formas de base nominal (Vossa Mercê e $O$ Senhor).

\section{As formas nominais de tratamento na posição de sujeito: cartas pernambucanas (1869-1969)}

Em termos da totalidade de dados levantados, observamos que, em nossa amostra de cartas pessoais pernambucanas relativas ao período de 1869-1969, foram identificados 589 dados de formas de tratamento de $2^{\mathrm{a}}$ pessoa na posição de sujeito, sendo 482 dados de você, 96 dados de $t u$, 5 dados de Vossa Mercê e 6 ocorrências de O/A senhor(a), conforme consta na Tabela 1 . No cômputo geral de você e $t u$, foram incluídos os dados de formas imperativas, assim distribuídas: 203 ocorrências de imperativo afirmativo e negativo pertencentes ao paradigma de você (esqueça / não se esqueça) e 32 ocorrências do imperativo do paradigma de tu (esquece / não se esquece). ${ }^{8}$

\footnotetext{
${ }^{8}$ Embora tenhamos controlado separadamente, incluímos os dados de imperativo no cômputo geral da Tabela 1. Na Tabela 2, os dados aparecem separadamente em duas colunas (não-imperativo e imperativo) para que se tenha uma visão panorâmica dos dados da amostra. Consideramos, entretanto, que as formas imperativas mereçam um estudo a parte, por conta de aspectos de natureza variada (preenchimento do sujeito, natureza do gênero em si, tradição discursiva, etc.), que não serão abordados neste momento, tendo em vista os limites deste estudo. Para mais detalhes, ver Lopes (2011).
} 
Tabela 1 - Distribuição das formas de tratamento na posição de sujeito

\begin{tabular}{ccccc}
\hline & Você & Tu & Vossa Mercê & $\begin{array}{l}\text { O/A } \\
\text { senhor(a) }\end{array}$ \\
\hline $\begin{array}{c}\text { Tratamento na posição } \\
\text { de sujeito }\end{array}$ & $482 / 589$ & $96 / 589$ & $05 / 589$ & $06 / 589$ \\
& $82 \%$ & $16 \%$ & $1 \%$ & $1 \%$ \\
\hline
\end{tabular}

Fonte: as autoras.

Os estudos sobre o tema já mostraram que as formas Vossa Mercê e $O / A$ senhor(a) denotam traços de cortesia e respeito entre os interlocutores deste gênero textual e de outros materiais. No estudo de Lopes e Duarte (2003), com base em peças teatrais brasileiras e portuguesas, as autoras também identificaram tais estratégias marcando as relações de inferior a superior com uma ligeira diferença de comportamento. Nas peças produzidas no Brasil, houve uso majoritário de Vossa Mercê, e em peças escritas em Portugal, o predomínio foi de $O$ Senhor / A senhora e de outras formas nominais. O esvaziamento do conteúdo cerimonioso da forma Vossa Mercê, nos séculos 18 e 19, já foi registrado por Rumeu (2004), com o aumento de sua produtividade em cartas não oficiais a partir do século 19.

$\mathrm{Na}$ amostra analisada, todas as ocorrências de Vossa Mercê e $O$ / A senhor(a) foram identificadas nas cartas de missivistas masculinos e adultos. Quanto ao subgênero, os registros dessas formas estão em cartas pessoais entre amigos e familiares, filho e pai, excluindo, desse modo, as relações mais íntimas estabelecidas nas cartas amorosas. Embora sejam pouquíssimos dados, cabe-nos analisar a motivação para o emprego de formas tratamentais oriundas de sintagma nominal, observando quem as empregou, em que momento histórico, para quem e qual o efeito pretendido.

No caso do emprego da forma $O$ Senhor, todos os seis dados ocorreram em uma só correspondência enviada por Joaquim Nabuco ao amigo Dr. Galvão, no início do século 20. Computamos aqui apenas os casos de sujeitos plenos e nulos, mas destacamos em [1] os casos de possessivo, clítico e imperativo que mantêm a simetria com a forma tratamental empregada, caracterizando a escrita de um escrevente de elevado grau de escolaridade, como é o caso do jurista Joaquim Nabuco: 
[1] Meu caro Colega Dr. Galvão, Acabo de ler os versos do seu [ilegível] < filho $>$ poema "A morte da Aguia" e venho felicital-o pela $\langle\uparrow$ belleza $>$ grandeza do mytho que $\boldsymbol{o} \boldsymbol{S} \boldsymbol{r}$. creou. Faço, se me permitte a franquesa, al- gumas reservas quanto <个ilegivel $>$ á deco- los á decoração litteraría e [ilegível] litteraría e mythologicos logíca do do quadro, em que o $s \boldsymbol{r}$. Traçou de mas em si mesma a creação [ilegível] me figura parte ${ }^{2}$ [espaço] e o meio da inspiração poderosa e original $<\uparrow$ visível $>$ se assim $<\downarrow$ e alguns $>$ clarões que illuminam e dos raios que o cruzam mostram que o S r . pertence a essa família e apenas contou o ideal da sua morte, que espero será muito diversa. Para isto seria bom acostumar a águia que $\boldsymbol{o} \boldsymbol{S} \boldsymbol{r}$. tem em si a visitar as Ca- tacumbas. Alem d morte pagou há morte Chrístan. Creia-me seu Patricio e amigo [rubrica] Joaquim Nabuco. (Carta JN 14, 20/03/1903) (ATAÍDE; GOMES, 2014).

Nessa carta, o vocativo já se encarrega de expressar um tom respeitoso ao se dirigir ao colega pela utilização do título de "Doutor", acompanhado do sobrenome. Esse tom mantém-se ao longo da missiva, mas aparece com menos distanciamento no fechamento da carta, ao alçar o destinatário da posição de colega a de amigo. O tratamento pareceunos no contexto discursivo bastante adequado, em função do conteúdo da carta marcado pelo comentário crítico a um poema produzido pelo destinatário. A polidez e a cortesia expressas pela forma tratamental adotada também ficam explícitas na introdução da crítica feita à obra "Faço, se me permite a franquesa, algumas reservas quanto...". A escolha tratamental e esse preâmbulo teriam o propósito de atenuar o ato da crítica, funcionando, na perspectiva de Brown e Levinson (1987) e seguidores, como uma estratégia de polidez que evitaria o conflito entre os interactantes.

No caso dos dados de Vossa Mercê, chamou-nos atenção o distanciamento temporal dos dois documentos em que essa forma apareceu. Em [2], as ocorrências situam-se no ano de 1869 (século 19) e, 
em [3], temos uma carta do final da década de 1950 (século 20), quase 100 anos depois:

[2] Mio querido Pae - deixe-me sua benção. Recebi a carta de Vosmecê com Data de 25 do corrente e fico inteirado de tudo quanto nella Vosmecê me mandou diser. Remeto hoje cosido em uma estopa a roupa suja que aqui havia - segundo me ordena Vosmecê em sua carta. [...] Recomendamos a todos, lanse sua benção a meos manos [inint.] sempre. Seo filho muito [amado] José Mariano (Carta JM 01, 27/04/1869) (GOMES, 2014).

[3] Meu caro Prof. Gilberto Freire: Conforme combinamos aí vão algumas copias do seu magnifico prefacio ao "Morão, Rosa e Pimenta" - bem como os respectivos originais datilografados. Gostaria de, quando me mandasse o exemplar definitivo para impressão, receber os originais manuscritos para a exposição que será feita no lançamento do volume. Junto envio uma copia da despretenciosa "nota do editor". Gostaria que passasse os olhos nessa pobre nota. O que penso do seu magnifico pre facio será dito em viva voz. Quem sabe se um jantarzinho de três ou quatro casais, no máximo, não seria oportuno para conversar sobre a materiá? A Maria da Penha está convalescendo de uma violenta pneumonia que veio forte. Logo que tudo se normalize combinaremos os por-menores se o meu caro amigo e senhora concordarem. Eu e Maria da Penha formulamos para vossa mercê e toda a sua Família os melhores votos de Ano Novo. Deus guarde vossa mercê

Jordão Emerenciano (Carta GF 09, 1958) (TRAVASSOS; GOMES, 2014).

Em [2], temos uma missiva enviada por José Mariano (jornalista) ao seu pai. O vocativo e a captação da benevolência, na abertura, revelam a afetividade e a proximidade respeitosa estabelecida entre os 
dois interlocutores "Mio querido Pae - deixe-me sua benção". O tratamento mais respeitoso que cerimonioso evidenciado pelo uso de Vosmecê é mantido do início ao fim da carta. O emprego da variante representada na carta como Vosmecê evidencia uma das etapas de erosão fonética sofrida pelo tratamento original Vossa Mercê. Tal uso elucida também o desgaste semântico do tratamento base rumo a um traço mais interpessoal que será assumido por você em outra fase do seu processo de mudança. De qualquer forma, a escolha dessa variante não é aleatória e marca ainda uma relação de poder denotada pela assimetria entre filho e pai, percebida também na construção com o verbo ordenar "Remeto hoje cosido em uma estopa a roupa suja que aqui havia - segundo me ordena Vosmecê em sua carta. (...)".

Em [3], reproduzimos trechos de uma carta enviada por Jordão Emerenciano (Bacharel em Direito e membro da Academia Pernambucana de Letras) a Gilberto Freyre. O conteúdo da carta pode ser dividido em dois blocos. O primeiro, iniciado pelo vocativo que se reporta a uma titulação do interlocutor, "Prof. Gilberto Freire", diz respeito à editoração de um livro, e o missivista envia a nota do editor para submissão do olhar do autor. Esse ato de solicitação é feito com certa dose de polidez, com o emprego do futuro do pretérito e do adjetivo que antecede o termo nota "(...) Gostaria que passasse os olhos nessa pobre nota...". Esse tom mais solícito cede lugar a um tom mais informal, no segundo bloco da carta, quando o missivista sugere um "jantarzinho" entre casais amigos, para discutir a matéria em questão. O emprego do diminutivo e a sequência de tópicos referentes ao contexto familiar (saúde da esposa e felicitações de ano novo em nome do casal) expressam uma emotividade e uma proximidade aparentemente incompatíveis com a forma tratamental empregada. Resta-nos, no bojo dos comentários referentes a um tom mais informal do segundo trecho da carta, compreender o emprego da forma tratamental Vossa Mercê em plena segunda metade do século 20: um uso que não retrata a norma linguística predominante nesse período e nesse contexto.

No viés das Tradições Discursivas, tal uso se justifica pela natureza e historicidade do texto. Como é possível perceber na leitura da carta, o emprego de Vossa Mercê deu-se com uma intenção comunicativa específica e numa seção da carta bastante fixa: a despedida. O missivista 
escreve primeiramente "Eu e Maria da Penha formulamos para vossa mercê e toda a sua Família os melhores votos de Ano Novo", com o intuito de captar a benevolência do destinatário e, logo em seguida, se despede: "Deus guarde vossa mercê". Trata-se, pois, de uma prática convencional das missivas de sincronias passadas, ou seja, configura-se como uma Tradição Discursiva, uma parte constitutiva da carta que guardou uma tradição de uso das formas tratamentais mais cerimoniosas. Essa prática tem registros, por exemplo, nas cartas administrativas que faziam o circuito luso-brasileiro do Arquivo Histórico Ultramarino do século 18.

Como mostram os exemplos comentados, as formas Vossa Mercê e $O$ Senhor tiveram incidência bastante reduzida em relação às formas pronominais ( $t u$ e você) no nosso recorte temporal e documental. Seu emprego apresenta claramente motivações de ordem sociopragmática e da natureza do texto. Passemos aos tópicos seguintes nos quais veremos o cenário de variação das formas pronominais tu-você na posição de sujeito.

\section{0 uso de tu e você na posição de sujeito em cartas pernambucanas: 1869-1969}

O acompanhamento do tratamento pronominal na escrita epistolar em Pernambuco consiste em um recorte diatópico, cujo resultado será incorporado ao mapeamento realizado em diferentes localidades do Brasil acerca do sistema de tratamento pronominal de segunda pessoa (2P). Com o levantamento dos dados pernambucanos, tínhamos o propósito de verificar se havia o predomínio do pronome $t u$ na posição de sujeito, como ocorre, por exemplo, no Rio Grande do Sul, se predominava você, como em Minas Gerais e São Paulo, ou se havia a simultaneidade no uso de você e tu na posição de sujeito, como ocorre no Rio de Janeiro (LOPES, RUMEU; CARNEIRO, 2013). Quisemos observar se havia, na documentação remanescente do período, vestígios das diferenças atuais no sistema pronominal do português brasileiro, em particular, do subsistema em vigor em Pernambuco (você e $t u$ ). 
Em termos dos resultados globais da variação entre você e $t u$ na posição de sujeito, localizamos 578 dados na amostra de cartas em um período de 100 anos de produção escrita dos missivistas analisados. O maior número de ocorrências foi de você com 482 dados $(83,4 \%)$, contra apenas 96 dados de $t u(16,6 \%)$. A distribuição desses dados ao longo do tempo mostra-nos, entretanto, que a coexistência das duas estratégias de referência à segunda pessoa apresentou um comportamento diferenciado, como pode ser visto no Gráfico 1:

Gráfico 1 - Distribuição de frequência de você e $t u$ na posição de sujeito em cartas pernambucanas (1869-1969)

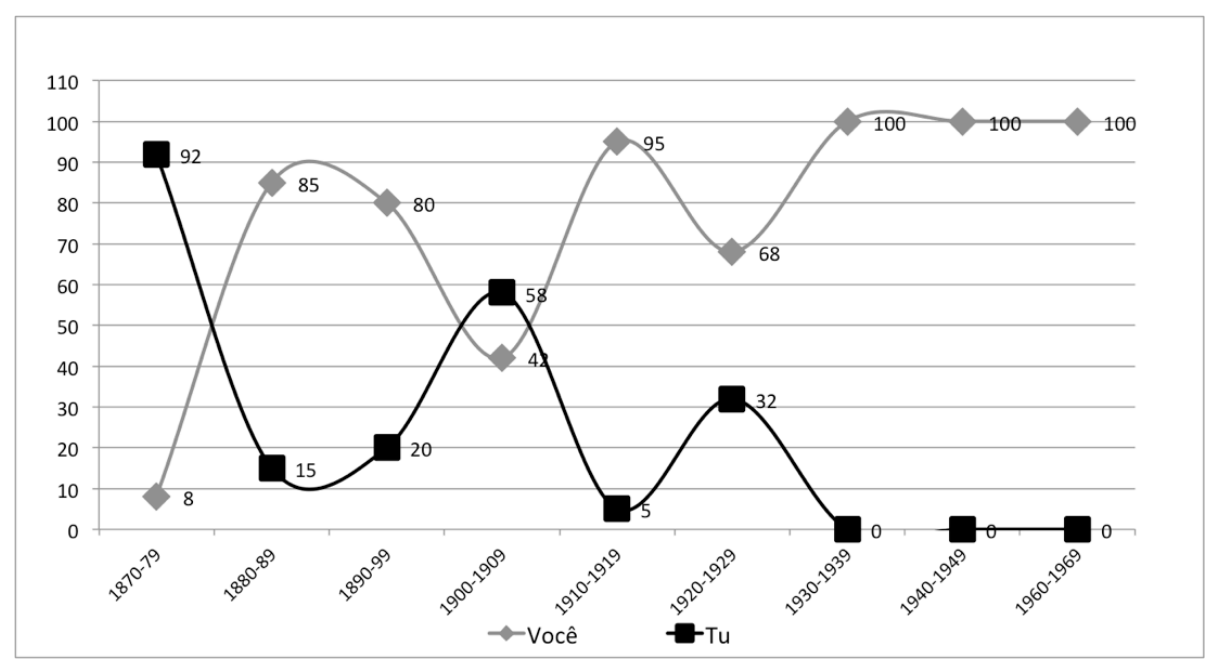

Fonte: as autoras.

O Gráfico 1 indica o forte predomínio, nas cartas pernambucanas, da estratégia mais frequente (você) em vários momentos, com índices de frequência acima de $60 \%$. Podemos perceber, entretanto, alguns aspectos interessantes das duas formas em competição ao longo do tempo:

- $\quad$ supremacia de $t u(92 \%)$ em fins do século 19 (1870-79);

- $\quad$ predomínio de você entre 1880-1900; 
- forte coexistência de $t u$ e você em dois períodos da primeira metade do século 20: década de 1900-10 e décadas de 1920-29; e

- generalização de você a partir de 1930.

Cabe destacar que tal comportamento, observado nessa amostra de cartas pernambucanas, não difere substancialmente do que foi detectado, para o mesmo período, em outras localidades brasileiras. Quando são sobrepostas, em um único gráfico, as linhas que marcam as frequências de você em relação a $t u$, verificamos certa regularidade ao longo do século 20 que poderia configurar um indício de mudança por três grandes fases:

Gráfico 2 - Síntese da difusão de você sujeito em diferentes localidades brasileiras

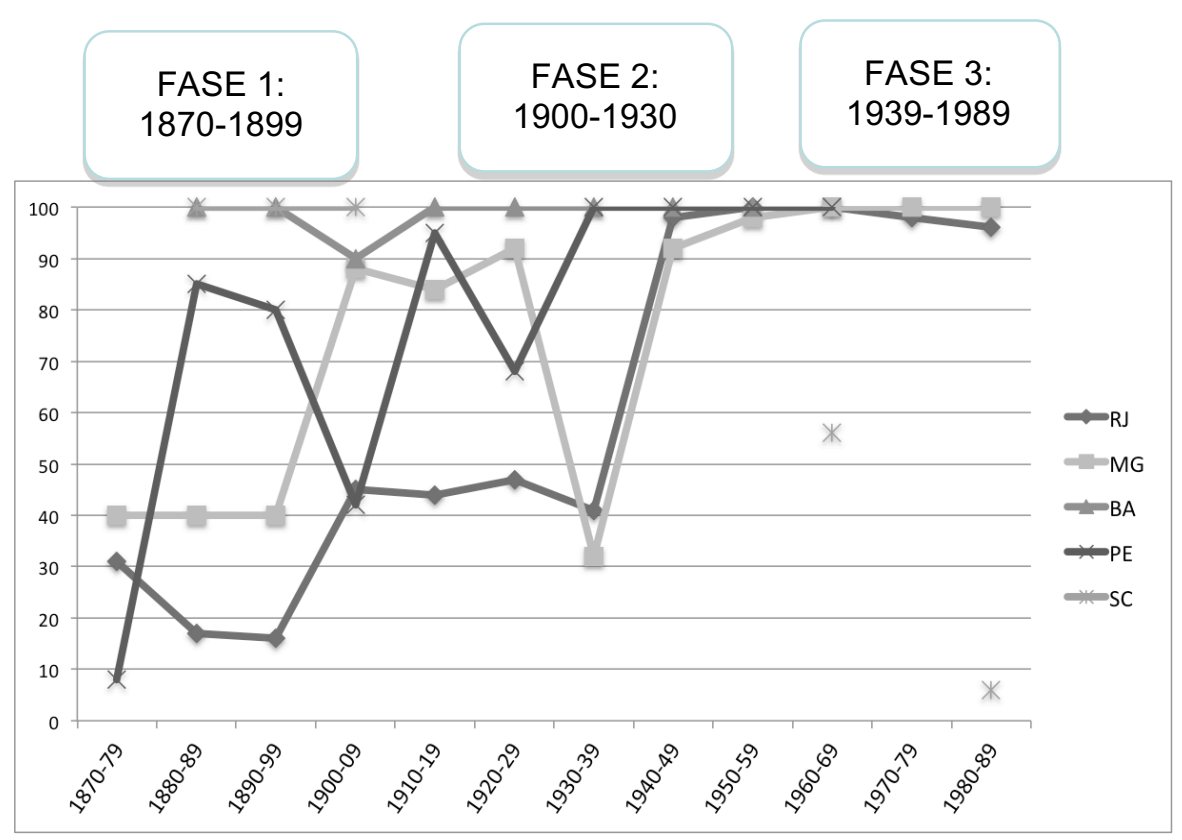

Fonte: as autoras. 
Embora haja diferenças regionais na difusão de você, percebemos uma tendência para a generalização ou ampliação do seu uso, ao longo do século 20, nos materiais analisados até aqui, referentes às regiões Sudeste (Rio de Janeiro e Minas Gerais), Nordeste (Bahia e Pernambuco) e, um pouco menos, na região Sul (Santa Catarina). ${ }^{9}$

Mesmo com taxas de frequência distintas, além de outros fatores, como a história particular de cada área, natureza da documentação e o perfil social dos missivistas, é possível delinear três grandes fases, como postulou Souza (2012):

Fase 1: 1870-1899: tu era mais frequente que você.

Fase 2: 1900-1939: tu e você em plena variação.

Fase 3: 1940-1989: Predomínio de você sobre $t u$.

Para compreender como se deu a difusão de você nas cartas pernambucanas, verificada no Gráfico 1, observaremos os fatores sociopragmáticos motivadores, tendo em vista as relações de poder e solidariedade estabelecidas e controladas com base no grau de parentesco e nos papéis sociais assumidos pelo remetente e destinatário das missivas:

${ }^{9}$ Esses resultados foram sintetizados por Lopes e Rumeu (2014) e apresentados no XVII Congresso da ALFAL, realizado em João Pessoa em 2014. Os resultados de Minas Gerais, Bahia e Rio de Janeiro constam de Lopes, Rumeu e Carneiro (2013). Os resultados de Santa Catarina são de Souza e Coelho (2013). 
Tabela 2 - Distribuição das formas de tratamento nas relações entre os informantes

\begin{tabular}{|c|c|c|c|c|c|c|c|}
\hline \multirow{2}{*}{\multicolumn{2}{|c|}{$\begin{array}{l}\text { Tipo de relação } \\
\text { entre informantes }\end{array}$}} & \multirow{2}{*}{$\begin{array}{c}\text { Grau de } \\
\text { Parentesco }\end{array}$} & \multicolumn{3}{|c|}{ Você } & \multicolumn{2}{|c|}{$\mathrm{Tu}$} \\
\hline & & & $\begin{array}{c}\text { Não- } \\
\text { imperativo }\end{array}$ & \multicolumn{2}{|c|}{ Imperativo } & $\begin{array}{c}\text { Não- } \\
\text { imperativo }\end{array}$ & Imperativo \\
\hline \multirow{6}{*}{\multicolumn{2}{|c|}{ Relações simétricas }} & \multirow[t]{2}{*}{ Amigos } & 82 & 36 & & 22 & 06 \\
\hline & & & \multicolumn{3}{|c|}{$118 / 146-80,82 \%$} & \multicolumn{2}{|c|}{$28 / 146-19,18 \%$} \\
\hline & & \multirow[t]{2}{*}{ Irmãos } & \multirow{2}{*}{\multicolumn{3}{|c|}{\begin{tabular}{|c|}
21 \\
$38 / 39-97,43 \%$
\end{tabular}}} & -- & 01 \\
\hline & & & & & & \multicolumn{2}{|c|}{$01 / 39-2,57 \%$} \\
\hline & & \multirow[t]{2}{*}{ Primos } & \multirow{2}{*}{\multicolumn{3}{|c|}{$21 / 21-100 \%$}} & -- & -- \\
\hline & & & & & $21 / 21-100 \%$ & \multicolumn{2}{|c|}{--} \\
\hline \multirow{2}{*}{\multicolumn{2}{|c|}{ Simétricas (casal) }} & \multirow{2}{*}{$\begin{array}{l}\text { Marido- } \\
\text { mulher }\end{array}$} & \multicolumn{3}{|l|}{01} & 01 & 04 \\
\hline & & & \multicolumn{3}{|c|}{$07 / 12-58,3 \%$} & \multicolumn{2}{|c|}{$05 / 12-41,7 \%$} \\
\hline \multirow{8}{*}{$\begin{array}{l}\text { Rela- } \\
\text { ções } \\
\text { assimé- } \\
\text { tricas }\end{array}$} & \multirow{4}{*}{$\begin{array}{l}\text { Descen- } \\
\text { dentes }\end{array}$} & \multirow{2}{*}{$\begin{array}{l}\text { Mãe- } \\
\text { filho }\end{array}$} & \multirow{2}{*}{\multicolumn{3}{|c|}{$11 / 14-7857 \%$}} & - & 03 \\
\hline & & & & & $11 / 14-78,57 \%$ & \multicolumn{2}{|c|}{$03 / 14-21,42 \%$} \\
\hline & & \multirow{2}{*}{$\begin{array}{l}\text { Pai- } \\
\text { filho }\end{array}$} & \multicolumn{3}{|c|}{58} & 29 & 13 \\
\hline & & & \multicolumn{3}{|c|}{$106 / 148-71,7 \%$} & \multicolumn{2}{|c|}{$42 / 148-28,3 \%$} \\
\hline & \multirow{4}{*}{$\begin{array}{l}\text { Ascen- } \\
\text { dentes }\end{array}$} & \multirow{2}{*}{$\begin{array}{l}\text { Filho- } \\
\text { mãe }\end{array}$} & \multirow{2}{*}{\multicolumn{3}{|c|}{$174 / 191-91 \%$}} & 12 & 05 \\
\hline & & & & & & $17 / 1$ & $-9 \%$ \\
\hline & & Filho- & 01 & & 06 & -- & -- \\
\hline & & pai & $07 / 07$ & $100 \%$ & & & \\
\hline & & TOTAL & 279 & 203 & & 64 & 32 \\
\hline & & & $482 / 57$ & $83,4 \%$ & & $96 / 578$ & $16,6 \%$ \\
\hline
\end{tabular}

Fonte: as autoras.

$\mathrm{Na}$ Tabela 2, as relações foram divididas em simétrica e assimétrica. As relações simétricas correspondem aos informantes que mantêm um contato de igualdade, como ocorre entre irmãos, primos e amigos. As relações assimétricas consistem nos contatos estabelecidos entre interlocutores que ocupam posições hierárquicas de distanciamento. As relações assimétricas descendentes ocorrem, por exemplo, de pai / mãe para filho(a); já as relações assimétricas ascendentes ocorrem, por exemplo, de filho(a) para pai / mãe. 
Observando a totalidade dos dados, verificamos, como já discutido, o predomínio de você nas variadas relações observadas nas cartas pernambucanas (acima de $70 \%$ na maior parte delas, com exceção da relação entre marido / mulher). Essa predominância confirma que a forma inovadora você teve sempre um comportamento híbrido, o que pode ter facilitado sua generalização no PB. Vemos, em nossa amostra, como já foi observado em outros estudos, o termo você que, ora marcava mais intimidade, como a carta escrita por Izabel Maria Fragoso para a filha Maria Fragoso Orlando da Silva, em [4], ora funcionava como estratégia de respeito, como na correspondência de Waldemar de Oliveira para a sua mãe, solicitando dinheiro para a sua manutenção na Bahia, durante o curso de medicina, em [5].

[4] Minha Filha

Todos os dias espero receber carta sua perguntei a Joãosinho disce elle q' voce a muito não escreve a elle q' já se esqueceo de escrever não basta o cuidado q' tenho em Eduardo. (...) (Carta AO 06, 06/09/1895) (FRAGA; GOMES, 2014).

[5] Minha querida mamãe (...) Não podia voce mandar me na segunda-feira, alguma cousa em carta não registrada? Seria um bom allivio para mim e estou bem certo não seria grande transtorno para você, pois se estivesse ahi, você me dando 200\# diarios e 1000 semanaes, só me tinha dado 6.800, quantia inferior ao que me tem mandado. Já vê que sobre materia de dinheiro, não lhe estou dando grandes prejuisos. (...) (Carta WO 13, 23/11/1916) (SILVA; GOMES, 2014).

O emprego eventual de $t u$ foi detectado nas relações assimétricas entre pais e filhos. Nas relações simétricas, tu ocorre, como previsto, nas relações íntimas entre amigos. Entre casais, os índices de $t u$ são os mais altos da tabela $(41,7 \%)$ que foram alavancados, entretanto, pela presença de formas imperativas. No que se refere aos dados de formas não imperativas, localizamos apenas um dado de $t u$ e outro de você que serão discutidos oportunamente. 
Em função de o uso variável ocorrer somente nessas relações, observaremos, no Gráfico 3, de dispersão, os índices de $t u$ ao longo do tempo. Os exemplos também darão destaque à forma menos frequente, para que sejam discutidos os contextos motivadores de seu emprego em uma amostra com supremacia quase absoluta de você:

Gráfico 3 - Frequência de $t u$ nos eixos temporal e social

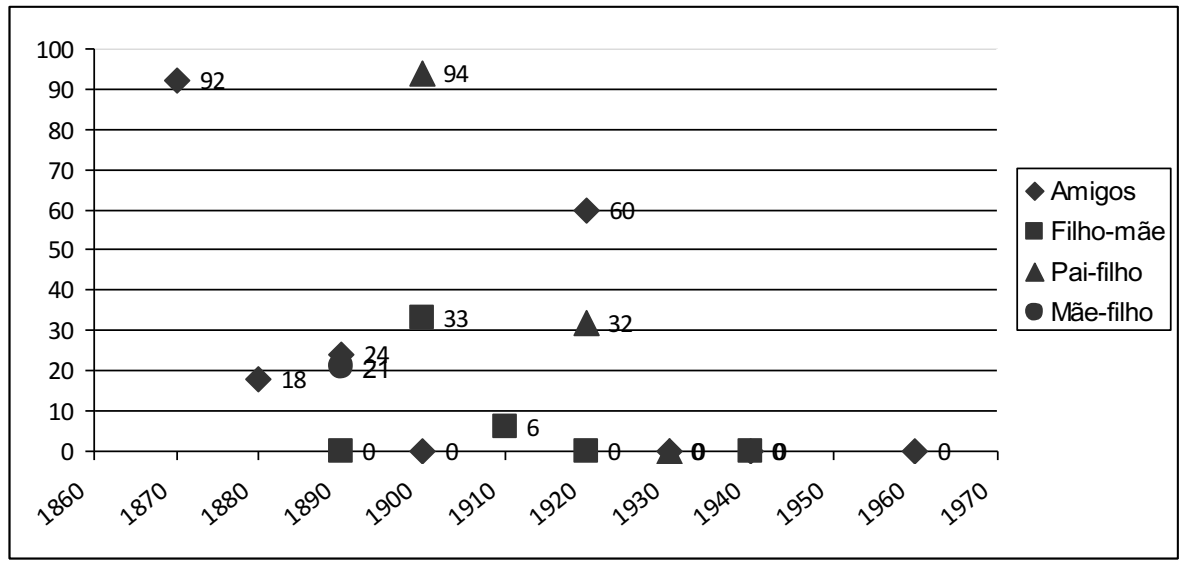

Fonte: as autoras.

Os resultados do Gráfico 3 confirmam o que foi observado em outros estudos sobre as formas de tratamento de 2P (RUMEU, 2013; SOUZA, 2012). Em fins do século 19 e na primeira metade do século 20, a forma $t u$ era empregada, também nas cartas pernambucanas, nas relações mais íntimas entre amigos (92\%). Em [6], temos um exemplo de $t u$, utilizado em uma correspondência trocada entre amigos numa relação solidária. Trata-se de uma carta escrita por Joaquim Nabuco ao amigo Salvador, para solicitar um favor. A forma carinhosa com que o escrevente se dirige ao destinatário é marcada, desde seu início, pelo tom afetivo da saudação (Meu caro Salvador):

[6] Meu caro Salvador,

(...) Ela é cunhada de Mistress Hallek aviuva do celebre general, e por qualquer modo $\boldsymbol{t} \boldsymbol{u}$ saberás onde encontral-a. Na carta fallo em ti, e Ella, desejará muito 
conhecer te pelo que eu lhe digo, e estou certode que será um muito agradável conhecimento para ambos. Adeus, meu caro Salvador. Cada dia mais eu te invejo - fazendo votos para que não voltes tão cedo á esta $<\uparrow$ capital $>$ do café. (...) (Carta JN 02, 25/12/1875) (ATAÍDE; FORCIONE, 2014).

A partir de 1870, entretanto, os índices de tu sofreram um declínio acentuado nas cartas destinadas a amigos: 18\%, em 1880;24\%, em 1890; 0\%, de 1990 em diante. Em 1920, contudo, temos novamente uma esporádica ascendência de $t u$ nesse tipo relação $(60 \%)$.

Outro aspecto que reitera o que foi observado nos estudos sobre o tratamento no PB é a presença do $t u$ nas relações assimétricas de superior / inferior (pai / filho). No Gráfico 3, observamos uma frequência alta, apenas em 1900: (94\%). Em 1930, os índices de $t u$ nessa relação atingem $32 \%$ apenas. O uso de $t u$ nas cartas entre mãe / filho ocorreu em 1890, com 21\% de frequência. Em [7], temos um dado extraído de uma correspondência de pai (José Mariano) para filha (Yayá). Trata-se de uma relação assimétrica descendente (pai / filha), mas com forte presença de marcas solidárias e de intimidade: uso de um adjetivo qualificativo (querida) e diminutivo (filhinha) na saudação; tom afetuoso e melancólico na despedida quando o pai pede por notícias (fico triste):

[7] Minha querida filhinha Yayá.

(...) Vi portanto porque saudaste essa que não chegou aqui. Já estou inteiramente bom. Foi bom que me mandasses o retalho d'A concentracão que é para eu mandar um cartão de felicitações ao [inint.] e não sahir em falta maior. Eu devia ter telegraphado mas passoume a data. Não deixes de me escrever sempre. Fico triste quando chega um vapor e não me traz noticias dahi. (...) (Carta JM 04, 13/07/1900) (GOMES, 2014).

Nas relações assimétricas de inferior / superior, houve menor presença de $t u$ como era esperado. No Gráfico 3, vemos, na década de 1900, 33\% de tu em cartas de filho para mãe. Em [8], Mário Sette se 
dirige a sua mãe com formas do paradigma de tu (podes), dando notícias sobre as reconciliações familiares depois de um desentendimento entre os membros de duas famílias. Em [9], apesar do tom afetivo e íntimo, o estudante de medicina Waldemar de Oliveira emprega você para tratar sua mãe:

[8] Minha adorada mãe.

Abençoe a mim e a Maria Laura. Até a presente data ainda não recebi uma carta escripta por ti, felicidade que anciosamente aguardo, como bem podes calcular. (...) (Carta MS 01, 16/11/1905) (FALCÃO; GOMES, 2014).

[9] Minha Querida Mamãe Como tem passado? Eu sahi doente, ás 11 horas hontem Porque você não veio a Communhão hontem? (Carta WO 01, 14/10/1907) (SILVA; GOMES, 2014).

A partir das décadas de 1930-40, a presença de $t u$ tornou-se bastante rara ou quase inexistente nas cartas pernambucanas. Fica evidente que houve, desde então, uma mudança de comportamento com a difusão de você nos contextos discursivo-funcionais mais típicos do íntimo $t u$.

Cabe ainda comentar, por fim, aspectos relacionados à atuação conjunta desses diversos fatores discutidos: o papel social, o valor discursivo-pragmático variável das formas de tratamento e a interferência do subgênero da carta nos resultados observados.

Embora tenhamos observado nas cartas pessoais analisadas uma elevada simetria no tratamento, justificada pelo alto grau de escolarização dos missivistas estudados, foi possível detectar o emprego, ora de $t u$, ora de você, em cartas diferentes, mas escritas pelo mesmo missivista a um único destinatário. Trata-se de duas cartas trocadas por um casal. Como pode ser visto em [10] e [11], o conteúdo da carta definiu, com base na sua temática, o emprego de um tratamento mais íntimo (formas do paradigma de $t u$ ) ou menos íntimo (predomínio de formas do paradigma de você). As duas cartas amorosas foram enviadas por Arthur Orlando à esposa, Maria Fragoso Orlando da Silva. A 
primeira carta, escrita em 1908, em [10], traz declarações amorosas e íntimas do casal; a segunda, também escrita em 1908, em [11], trata da compra de um imóvel.

[10] Recife, 2 de Novembro de 1908

[...] Não tenhas medo, minha febre não é paludismo, é loucura por ti. Vem ver-me e olhar muito para mim. Não te esqueças de que é com as linhas de teus braços e com a cor de teus olhos que minha alma vai todos os dias desenhando o seu ideal. Arthur Orlando (Carta AO 16, 02/11/1908) (FRAGA; GOMES, 2014).

[11] Recife, 5 de $9^{\text {bro }}$ de 1908

Minha Babona

Fui à Varzea e lá encontrei uma casa, no pateo das Egrejas, com jardim ao lado, grande sitio e abacateiros e laranjeiras e cajueiros e figueiras e videiras, e groselheiras, e videiras e grande cosinha com grande fogão de ferro, tanque, latrina, tudo por 100 Réis, garantindo por 3 mezes, ao todo, por tanto, 300 Réis. Que acha? É preciso decidir quanto antes. Não se esqueça de mandar-me os meus Novos Ensaios. [...] Venha Babona. De teu velho babão. (Carta AO 17, 05/11/1908) (FRAGA; GOMES, 2014).

Em [10], o emprego exclusivo do tu condiz com o propósito comunicativo de expressar o afeto e a relação íntima do casal. Já em [11], as formas verbais em terceira pessoa (Que acha? Não se esqueça) remetem à interlocutora em segunda pessoa. Prevalece, nesse exemplo, o comunicado sobre a compra de uma casa, portanto, uma temática de menor intimidade. As expressões de proximidade e emotividade ficam evidenciadas no vocativo e na assinatura, com os pseudônimos "Minha Babona" e "De teu velho babão". Vale destacar a única ocorrência do possessivo "teu" do paradigma original de $2 \mathrm{P}$ em uma correspondência de construção exclusiva com formas do paradigma de você. Esse emprego tem uma explicação pragmática, uma vez que denota uma proximidade afetiva entre os interlocutores. 
Em suma, apesar de a forma você ter sido majoritária nas diferentes relações sociais ao longo do tempo, verificamos algumas fases em que a variação entre você e $t u$ imperou nas cartas pernambucanas: fins do século 19 (1870) e início do século 20 (1900-1910). O emprego de $t u$ era sociopragmaticamente motivado, ocorrendo, nas cartas pernambucanas, eventualmente, nas relações assimétricas descendentes, mas solidárias. Nas relações simétricas entre amigos, tal uso também se fez presente apenas nas últimas décadas do século 19 (1870-1899) e nos anos de 1920 quando o pronome tu perdeu efetivamente espaço para você.

\section{Considerações finais}

Com o propósito de adicionar os resultados obtidos na amostra de cartas pernambucanas dos séculos 19 e 20 aos demais estudos desenvolvidos por outras equipes brasileiras, esta pesquisa sóciohistórica visa contribuir com o entendimento da configuração do sistema pronominal do português brasileiro. Desse modo, retomamos os pontos norteadores iniciais.

O conceito de Tradição Discursiva mostrou-se relevante na explicação das mudanças ocorridas no sistema de tratamento pronominal do português brasileiro. O gênero "carta pessoal" apresenta repetição de fórmulas típicas em sua composição que retemem a usos pertencentes à natureza do texto. Algumas partes constitutivas das cartas favoreceram a permanência de formas tratamentais menos inovadoras (a abertura, a captação da benevolência, a despedida, por exemplo) e outras possibilitam mais a inserção de formas mais inovadoras (o corpo do texto). Assim, a carta configura-se como um documento propício para os estudos diacrônicos, em virtude da circunstância espontânea de comunicação verbal, mas conserva fórmulas fixas que precisam ser controladas para não interferir em pesquisas que buscam as normas de uso da língua no curso da história.

Além das partes constitutivas, os subgêneros da carta (familiar, pessoal e amorosa) revelam graus diferenciados de intimidade, confiança e emocionalidade que, consequentemente, interferem na escolha 
tratamental entre os interlocutores, favorecendo os contextos de variação entre as formas relacionadas ao paradigma de você e $t u$. A metodologia aplicada possibilitou identificar as formas tratamentais empregadas nos documentos pernambucanos, correlacionar com o resultado de outros estados do Nordeste, Sudeste e Sul e verificar as motivações dos usos vinculados às tradições do texto, aos fatores pragmáticos e aos indícios da norma linguística da época.

O traçado do perfil tratamental nas correspondências de Pernambuco possibilitou verificar que as formas oriundas de sintagmas nominais (Vossa Mercê e O/A Senhor/a), cuja incidência foi bastante reduzida dentro do nosso recorte temporal e documental, tiveram motivações de ordem pragmática e da natureza do texto.

$\mathrm{Na}$ análise da variação entre $t u$ e você na posição de sujeito, foi possível detectar particularidades das fontes documentais pernambucanas: predomínio de você, com usos bastante episódicos de $t u$ na primeira metade do século 20. Os períodos pontuais de variação, entretanto, demonstraram que, também nas cartas pernambucanas, o pronome $t u$ já foi empregado para relações bastante íntimas entre casais e nas relações assimétricas. Tais resultados não contradizem, assim, o que se tem observado em amostras de sincronias passadas de outras partes do Brasil estudadas. $\mathrm{O}$ estudo mostrou que houve nitidamente uma generalização de você nos diferentes tipos de relação, confirmando o seu caráter polifuncional encontrado desde o século 19. A forma inovadora de $2 \mathrm{P}$ se firmou, desde o início do século 20, como estratégia neutra para qualquer situação, acompanhando as mudanças nas relações sociais.

Outras amostras documentais e outras reflexões precisam complementar os resultados aqui apresentados, mas esperamos que os fatores extralinguísticos aqui analisados e discutidos possam contribuir para os estudos acerca da variação e da mudança do português brasileiro, no que diz respeito às formas tratamentais.

\section{Referências}

ATAÍDE, C.; FORCIONI, D. Cartas Pessoais do século XIX Pernambuco. Recife: Projeto PHPB /PE, 2010. Cartas: JN 2. 
ATAÍDE, C.; GOMES, V. S. Cartas Particulares - Pernambuco. Recife: Projeto PHPB /PE, 2014, Carta: JN 14

BARCIA, L. R. As formas de tratamento em cartas de leitores oitocentistas: peculiaridades do gênero e reflexos da mudança pronominal. 2006. Dissertação (Mestrado em Letras) - Faculdade de Letras, Universidade Federal do Rio de Janeiro, Rio de Janeiro, 2006.

BROWN, R.; GILMAN, A. The pronouns of power and solidarity. In: SEBEOK, T. A. Style in Language. Cambridge, MA: MIT Press, 1960. p. 253-276.

BROWN, L.; LEVINSON, S. Politeness: some universal in language usage. Cambridge: Cambridge University Press, 1987.

CONDE-SILVESTRE, J. C. Sociolinguística histórica. Madrid: Gredos, 2007.

FALCÃO, S. C. L.; GOMES, V. S. Cartas pessoais - Recife, Pernambuco. Recife: Projeto PHPB/PE, 2014. Carta MS 01.

FRAGA, I. P. de; GOMES, V. S. Cartas pessoais - Recife, Pernambuco. Recife: Projeto PHPB/PE, 2014. Cartas: AO 6; AO 16; AO 17.

GOFFMAN, E. A elaboração da face - uma análise dos elementos rituais da interação social. In: FIGUEIRA, S. (Org.). Psicanálise e Ciências Sociais. Rio de Janeiro, Francisco Alves, 1980.

HERNÁNDEZ-CAMPOY, J. M.; CONDE-SILVESTRE, J. C. The Handbook of Historical Sociolinguistics. Oxford, Wiley-Blackwell, 2012. p. 63-79. <http://dx.doi.org/10.1002/9781118257227>

GOMES, V. S. Cartas pessoais - Recife, Pernambuco. Recife: Projeto PHPB/PE, 2014. Cartas: JM 01; JM 04.

KABATEK, J. Tradiciones discursivas y cambio linguistic. In: CIAPUSCIO, G.; JUNGBLUTH, K.; KAISER, D.; LOPES, C. R. S. (Ed.). Sincronía y diacronia de tradiciones discursivas em Latinoamérica. Iberoamericana, Vervuert, 2006, p. 151-172. 
KOCH, P.; OESTERREICHER, W. Oralidade y escrituralidad a luz de la Teoria del Lenguage. In: . Lengua Hablada en La Romania: español, francés, italiano. Madrid; Editorial Gredos, 2007, p. 20-42.

$\mathrm{KOCH}$, Peter. Tradiciones Discursivas y Cambio Linguístico: el ejemplo del tratamiento vuestra merced en español. In: KABATEK, Johannes (Ed.) Sintaxis histórica del español y cambio lingüistico: Nuevas perspectivas desde las Tradiciones Discursivas. Madrid / Frankfurt: Iberoamericana / Vervuert (Linguística Iberoamericana 31), 2008. p. 5388 .

LABOV, W. Sociolinguistic Patterns. Philadelphia: University of Pennsylvania Press, 1972.

LOPES, C. R. dos S. Mudança gramatical do ponto de vista funcionalista: o capítulo dos pronomes. In: CONGRESSO INTERNACIONAL DA ABRALIN, 8, Natal. 30 jan.-2 fev. 2013. Anais... Mesa-redonda 16. História do Português Brasileiro, Natal, RN, 2013.

.Tradição discursiva e mudança no sistema de tratamento do português brasileiro: definindo perfis comportamentais no início do século XX. Alfa, São Paulo, v. 55, n. 2, p. 361-392, 2011.

LOPES, C. R. dos S.; CAVALCANTE, S. A cronologia do voceamento no português brasileiro: expansão de você-sujeito e retenção do clíticote. Revista Linguística, Madrid, v. 25, p. 30-65, 2011.

LOPES, C. R. dos S.; DUARTE, M. E. L. De "Vossa Mercê" a "Você": análise da pronominalização de nominais em peças brasileiras e portuguesas setecentistas e oitocentistas. In: BRANDÃO, S. F.; MOTA, M. A. (Org.). Análise contrastiva de variedades do português: primeiros estudos. Rio de Janeiro: In-fólio, 2003. p. 61-76.

LOPES, C. R. dos S.; RUMEU, M. C. de B.; CARNEIRO, Z. de O. N. A configuração diatópica-diacrônica do sistema de tratamento do português brasileiro. Revista do Grupo de Estudos Linguísticos do Nordeste, v. 15, n. 1/2, p. 187-212, 2013.

LOPES, C.R. dos S. e RUMEU, M.C. A entrada de você e a correlação entre sujeito e outras funções no Rio de Janeiro e em Minas Gerais. In: 
CONGRESSO INTERNACIONAL DA ALFAL, 27, João Pessoa. 14 a 19 jul. 2014. Anais..., João Pessoa, 2014.

MAIA, C. Linguística histórica e Filologia. In: LOBO, Tânia et. al. (Org.). Rosae: linguística histórica, história das línguas e outras histórias. Salvador: EDUFBA, 2012.

RUMEU, M. C. de B. Língua e sociedade: a história do pronome "você" no português brasileiro. Rio de Janeiro: Ítaca, 2013.

. A implementação do 'você' no português brasileiro oitocentista e novecentista: um estudo de painel. 2008. Tese (Doutorado em Língua Portuguesa) - Universidade Federal do Rio de Janeiro, Rio de Janeiro, 2008.

Para uma História do Português no Brasil: Formas Pronominais e Nominais de Tratamento em Cartas Setecentistas e Oitocentistas. 2004. Dissertação (Mestrado em Língua Portuguesa) Universidade Federal do Rio de Janeiro, Rio de Janeiro, 2004.

SILVA, A. S. e; GOMES, V. S. Cartas pessoais - Recife, Pernambuco. Recife: Projeto PHPB/PE, 2014. Cartas: WO 01; WO 13.

SOUZA, J. P. F. de. Mapeando a entrada do você no quadro pronominal: análise de cartas familiares dos séculos XIX-XX. 2012. Dissertação (Mestrado em Letras) - Universidade Federal do Rio de Janeiro, Rio de Janeiro, 2012.

SOUZA, C. M. N. de; COELHO, I. L. O sistema de tratamento em Santa Catarina: uma análise de cartas pessoais dos séculos XIX E XX. Revista do Grupo de Estudos Linguísticos do Nordeste, v. 15, n. 1/2, p. 213-244, 2013.

TRAVASSOS, T.; GOMES, V. S. Cartas pessoais - Recife, Pernambuco. Recife: Projeto PHPB/PE, 2014. Carta GF 09. 

